\title{
The Impact of Serum MicroRNA-21 on Outcome of Diffuse Large B-Cell Lymphoma Patients
}

\author{
SAMAR M. KAMAL EL-DIN, M.D.*; FATHIA I. EL-BASSAL, M.D.*; AMIRA M.F. SHEHATA, M.D.*; \\ AYMAN A. AZZAM, M.D.**; SAMAR E. GHANEM, M.D.**; EMAN A. TAWFIK, M.D.***; \\ SUZAN A. AL-HASSANIN, M.D.*** and SUZY F. GOHAR, M.D.*** \\ The Department of Clinical Pathology, Faculty of Medicine, Menoufia University*, \\ The Department of Clinical Biochemistry and Molecular Diagnostics, National Liver Institute** and \\ The Department of Clinical Oncology, Faculty of Medicine, Menoufia University***, Menoufia, Egypt
}

\begin{abstract}
Background: The emerging role of circulating microRNAs (miRNAs) as diagnostic and predictive tools has become fundamental and promising scope of cancer research. The link between the aberrant expressions of various miRNAs and the pathogenesis of Diffuse Large B-Cell Lymphoma (DLBCL) has been revealed by numerous studies.
\end{abstract}

Aim of Study: This study was planned to analyze the relative expression levels of serum miRNA-21 and to elucidate its potential prognostic significance in DLBCL patients who had received cyclophosphamide, doxorubicin, vincristine, prednisone plus rituximab (R-CHOP) regimen.

Patients and Methods: Serum miRNA-21 relative expression levels were analyzed by Polymerase Chain Reaction (PCR) based technique in 65 DLBCL patients prior to immunochemotherapy in comparison with 35 healthy individuals. Receiver operating characteristic curve analysis was used to determine the ideal miRNA-21 cutoff and Kaplan-Meier method was used to calculate the overall survival of DLBCL patients.

Results: MiRNA-21 expression levels were significantly up-regulated in DLBCL patients compared to healthy controls $(p<0.001)$. MiRNA-21 expression levels were closely associated disease stage, response to therapy, 32 microglobulin, Lactate Dehydrogenase (LDH) and C-Reactive Protein (CRP) $(p<0.001 ; p=0.042 ; p<0.001 ; p=0.003 ; p=0.02$ respectively). However, there was no relationship with other characteristics such as age, gender, extranodal site involvement, B symptoms, and International Prognostic Index (IPI) (all $p \mathrm{~s}>0.05$ ). Overall survival was significantly worse in patients with high miRNA21 expression levels compared to those with low expression levels $(p=0.01)$.

Conclusion: Serum miRNA-21 may be employed as valuable non-invasive prognostic marker in DLBCL patients treated with R-CHOP regimen.

Correspondence to: Dr. Fathia Ibrahim Hamed El-Bassal, E-Mail: drfathiabassal@yahoo.com
Key Words: Circulating microRNA-21 - Diffuse large B-cell lymphoma-Polymerase chain reaction - Prognosis.

\section{Introduction}

DIFFUSE Large B-Cell Lymphoma (DLBCL) is recorded as the most prevalent histological variant of Non-Hodgkin's Lymphoma (NHL) as it represents nearly one third of newly identified adult NHL cases [1]. DLBCL is characterized by diverse clinical presentation, histological features, immunophenotypic patterns and genetic characteristics, so variation in prognosis and response to therapy is anticipated [2].

With the current use of Rituximab-based immunochemotherapy, over fifty percent of patients with DLBCL are considered to be curable [3] However, there are some patients showing poor outcome even after recent therapy modalities and most of them suffer from refractory disease or relapse [4]. Therefore, it is essential to establish proper classification for DLBCL based on specific clinicopathological variables and new reliable prognostic markers, to ensure appropriate therapy for each patient [5]

MicroRNAs (miRNAs) are non-coding RNA molecules that play a major role in cell proliferation, differentiation and survival by binding to complementary target messenger RNA (mRNA), resulting in mRNA translational inhibition [6].

The discovery of miRNAs provides a new tool for the comprehension of DLBCL biology and the emergence of predictive biomarkers in DLBCL. Study of miRNA expression patterns may play essential role in identification of certain group of 
DLBCL patients with immunochemotherapy resistance and unfavorable clinical outcome $[7,8]$.

MicroRNA-21 (MiR-21) is one of the early identified and most widely investigated miRNAs [9]. Several studies reported its up-regulation in various hematological and solid-organ neoplasms such as cutaneous T-cell lymphoma, multiple myeloma, colorectal cancer and cervical cancer [1013]. Therefore, miR-21 may be utilized as a diagnostic and prognostic marker for human cancers [14].

MiR-21 acts as potent oncogene and has essential role in cancer initiation, progression and dissemination, through down-regulation of tumor suppressor genes [15]. We aimed to investigate the difference in the expression levels of circulating miR-21 between newly diagnosed DLBCL patients and normal apparently healthy individuals, and to assess the potential relation between miR-21 expression levels and prognosis of DLBCL patients.

\section{Patients and Methods}

After approval from Medical Ethics Committee of Menoufia University Hospitals, this prospective study was conducted on 65 patients with pathologically confirmed diffuse large B-cell lymphoma who presented to Oncology Department; Menoufia University Hospitals between December 2015 and June 2016. In addition, 35 healthy individuals were included and served as control group.

The recruited patients for the study received no previous chemotherapy or radiotherapy and had no major co-morbidities. Patients with comorbid major illness (e.g. hepatic, renal or heart diseases), performance status more than 2 or history of other cancer were excluded.

After providing written consent; all patients were initially subjected to history taking, clinical examination and investigations in the form of routine laboratory tests and Computed Tomography (C.T) imaging.

Baseline information was also collected including: Demographics, tumor characteristics (size and site of involved nodes, histological characteristics, history of B symptoms, and if extra-nodal sites were involved). Staging was based on Ann Arbor staging system.

All patients initially received Rituximabcyclophosphamide, doxorubicin, vincristine, and prednisone (R-CHOP) regimen. All patients were evaluated every cycle by clinical examination, routine laboratory investigations including LDH.
CT body was done every 2 to 3 cycles. Follow-up duration of all patients was at least 24 months from time of diagnosis. Patients' responses to R-CHOP regimen was assessed using response evaluation criteria and were categorized into Complete Response (CR), Partial Response (PR), Progressive Disease (PD) and Stable Disease (SD). Overall patient survival (OS) time was defined as the time from the date of immunochemotherapy initiation till last follow-up or death.

\section{Basic laboratory tests:}

Patients were investigated for Complete Blood Count (CBC) using Sysmex XN-10 Hematology Analyzer (Sysmex Corporation, Kobe, Japan); CReactive Protein (CRP) using CRP analyzer (HEALES, Shenzhen, China); Lactate Dehydrogenase (LDH), liver and kidney function by AU680 Chemistry Analyzer (Beckman Coulter Inc; Brea, California, USA); and beta2-microglobulin using mini VIDAS immunoanalyzer (Biomerieux, Marcy l'Etoile, France).

\section{MiR-21 expression levels analysis:}

Venous blood samples were withdrawn from controls and patients prior chemotherapy for miR21 testing. Three milliliters of blood were collected into plain vacutainer tube; left for about one hour at room temperature before being centrifuged at $3000 \mathrm{rpm}$ for $15 \mathrm{~min}$ at room temperature. The serum was preserved in Eppendorf tubes at $-80^{\circ} \mathrm{C}$ till analysis.

\section{MiR-21 extraction and reverse transcription:}

Total RNA was isolated from 200 microliters $(\mu \mathrm{L})$ serum using miRNeasy Mini Kit (Qiagen, Hilden, Germany) in accordance with the manufacturer's instructions. Isolated RNA quantity was measured spectrophotometrically by NanoDrop 2000 (Thermo Scientific, Wilmington, Delaware, USA). Isolated RNA was then reversely transcribed by TaqMan MiRNA Reverse Transcription Kit (Applied Biosystems, Foster City, California, USA).

\section{Real-time reverse transcription PCR ( $R T-q P C R)$ :}

Real-time PCR was achieved by TaqMan Universal Master Mix II Kit (Applied Biosystems). The expression of miR-21 was analyzed by ABI 7500 Real-Time PCR system (Applied Biosystems) with the subsequent reaction conditions: Initial at $95^{\circ} \mathrm{C}$ ( 10 minutes), 40 cycles at $95^{\circ} \mathrm{C}$ ( 15 seconds) and at $60^{\circ} \mathrm{C}$ (60 seconds). Reverse transcription and PCR primers were supplied by (Applied Biosystems); miR-21 (hsa-miR-21; ID 000397) (target gene) and U6 (U6 snRNA; ID 001973) (reference control gene). 
MiR-21 relative expression levels were calculated and normalized to U6 using the equation $2-\Delta \Delta \mathrm{CT}$; where $\mathrm{CT}$ is the threshold cycle; $\Delta \mathrm{CT}=\mathrm{CT}$ (target gene) $-\mathrm{CT}$ (reference gene) and $\Delta \Delta \mathrm{Ct}=$ $\Delta \mathrm{Ct}$ (tested sample) $-\Delta \mathrm{Ct}$ (control sample).

\section{Statistical analysis:}

Data were analyzed by SPSS Version 23 (IBM Corp, USA). Chi-square test ( $\left.\chi^{2}\right)$ was used to study association between qualitative variables. Mann Whitney's and student's $t$-test were used to compare quantitative variables in two groups of abnormally and normally distributed data respectively. Receiver Operator Characteristic (ROC) curve was employed in the assessment of specificity and sensitivity of miR-21 as predictive marker. Kaplan-Meier method with log rank test was done to estimate patients' Overall Survival (OS). $p$-values of less than 0.05 were considered significant.

\section{Results}

\section{Patient characteristics:}

A total of 65 DLBCL patients were included in our study. The median age was 55 (range: 1980) years, and $32(49.2 \%)$ were male. Regarding Ann Arbor stage, $44.6 \%$ of patients were in stage I or II, and $55.4 \%$ were in stage III or IV. $83.1 \%$ of patients had low or low-intermediate risk; while $16.9 \%$ had high-intermediate risk according to International Prognostic Index (IPI) scores (Table 1).

Table (1): Relation between miR-21 expression and clinical and laboratory characteristics of DLBCL patients.

\begin{tabular}{|c|c|c|c|c|}
\hline Characteristics & $\begin{array}{l}\text { Total } \\
(n=65)\end{array}$ & $\begin{array}{l}\text { Low miR-21 } \\
\qquad(\mathrm{n}=29) \\
\text { No. }(\%)\end{array}$ & $\begin{array}{l}\text { High miR-21 } \\
\qquad(\mathrm{n}=36) \\
\text { No. }(\%)\end{array}$ & $\begin{array}{c}p- \\
\text { value }\end{array}$ \\
\hline \multicolumn{5}{|l|}{ Gender: } \\
\hline Male & $32(49.2 \%)$ & $17(58.6)$ & $15(41.7)$ & 0.17 \\
\hline Female & $33(50.8 \%)$ & $12(41.4)$ & $21(58.3)$ & \\
\hline Age (years) a & $54.75 \pm 15.42$ & $52.10 \pm 17.68$ & $56.88 \pm 13.19$ & 0.40 \\
\hline \multicolumn{5}{|l|}{ Stage: } \\
\hline I-II & $29(44.6 \%)$ & $26(89.7)$ & $3 \quad(8.3)$ & $<0.001 *$ \\
\hline III-IV & $36(55.4 \%)$ & $3 \quad(10.3)$ & $33(91.7)$ & \\
\hline \multicolumn{5}{|l|}{ B symptoms: } \\
\hline Yes & $16(24.6 \%)$ & $7 \quad(24.1)$ & $9 \quad(25.0)$ & 0.93 \\
\hline No & $49(75.4 \%)$ & $22(75.9)$ & $27(75.0)$ & \\
\hline \multicolumn{5}{|l|}{ Performance status: } \\
\hline$<2$ & $60(92.3 \%)$ & $27(93.1)$ & $33(91.7)$ & 0.80 \\
\hline$\geq 2$ & $5 \quad(7.7 \%)$ & $2 \quad(6.9)$ & $3 \quad(8.3)$ & \\
\hline \multicolumn{5}{|l|}{ Extranodal site: } \\
\hline Yes & $36(55.4 \%)$ & $14(48.3)$ & $22(61.1)$ & 0.30 \\
\hline No & $29(44.6 \%)$ & $15(51.7)$ & $14(38.9)$ & \\
\hline \multicolumn{5}{|l|}{$I P I:$} \\
\hline $0-2$ & $54(83.1 \%)$ & $27(93.1)$ & $27(75.0)$ & 0.10 \\
\hline $3-5$ & $11(16.9 \%)$ & $2 \quad(6.9)$ & $9 \quad(25.0)$ & \\
\hline \multicolumn{5}{|l|}{$C R$ after $R-C H O P$ regimen: } \\
\hline Yes & $48(73.8 \%)$ & $25(86.2)$ & $23(63.9)$ & $0.042 *$ \\
\hline & $17(26.2 \%)$ & $4 \quad(13.8)$ & $13(36.1)$ & \\
\hline $\mathrm{CRP}(\mathrm{mg} / \mathrm{L})^{\mathbf{a}}$ & $40.43 \pm 20.21$ & $34.10 \pm 15.42$ & $45.25 \pm 22.28$ & $0.02 *$ \\
\hline $\mathrm{LDH}(\mathrm{U} / \mathrm{L})^{\mathbf{a}}$ & $428.37 \pm 231.63$ & $361.62 \pm 177.19$ & $512.13 \pm 250.18$ & $0.003 *$ \\
\hline$\beta 2$ microglobulin $(\mathrm{mg} / \mathrm{L}) \mathbf{a}$ & $3.57 \pm 1.68$ & $2.60 \pm 0.74$ & $4.34 \pm 1.82$ & $<0.001 *$ \\
\hline $\begin{array}{ll}\text { a } & : \text { Data are expressed } \\
\text { IPI } & : \text { International Progn } \\
\text { CR } & : \text { Complete Respons } \\
\text { R-CHOP } & : \text { Rituximab-cycloph } \\
\text { CRP } & : \text { C-Reactive Protein } \\
\text { LDH } & : \text { Lactate Dehydroge } \\
* & : \text { Statistically signifi }\end{array}$ & $\begin{array}{l}\text { mean } \pm \text { standard d } \\
\text { ic Index. } \\
\text { phamide, doxorubi }\end{array}$ & in, vincristine, and & prednisone. & \\
\hline
\end{tabular}


Serum miR-21 expression in DLBCL patients:

MiR-21 expression levels were significantly higher in DLBCL patients compared to those in the control group $(5.45 \pm 1.93$ versus $2.99 \pm 0.95$ respectively; $p<0.001$ ) (median: 5.23 ; range: 1.98 8.85 versus median: 2.88; range: $1.33-4.45)$ Fig. (1).

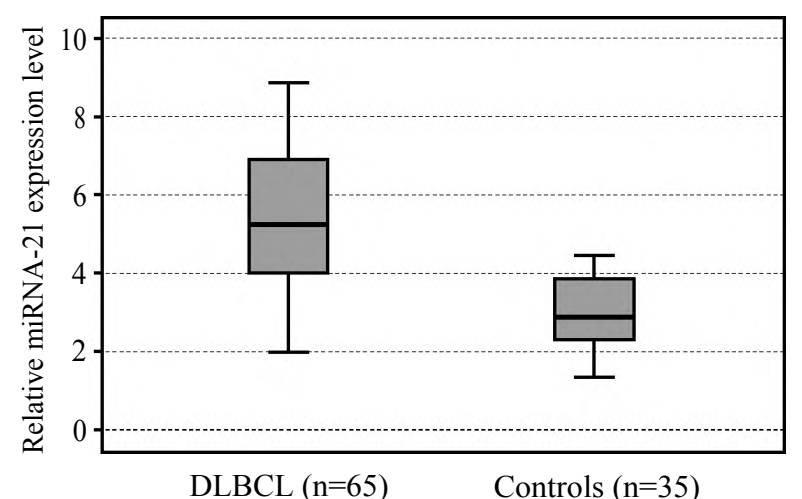

Fig. (1): Relative serum miR-21 expression level in DLBCL patients and healthy controls.

Optimal cut-off value for miR-21 and association between miR-21 expression levels and clinical and laboratory parameters:

The ROC curve for miR-21 was used to determine the cut-off value. Area Under the Curve (AUC) was 0.97 and optimal cut-off value was 4.97, with $91.0 \%$ sensitivity and $89.7 \%$ specificity Fig. (2). There were 29 patients with miR-21 expression levels less than 4.97 and 36 patients with miR-21 expression levels more than 4.97 .

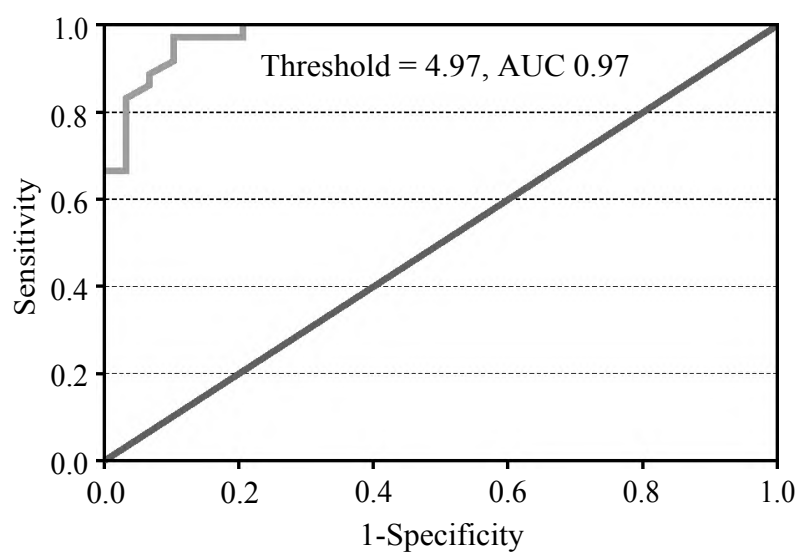

Fig. (2): Receiver Operating Characteristic (ROC) curve analysis for miR-21.

MiR-21 expression levels were closely associated with stage, C-Reactive Protein (CRP), Lactate Dehydrogenase (LDH), $\beta 2$ microglobulin and initial response to therapy $(p<0.001 ; p=0.02 ; p=0.003$; $p<0.001 ; p=0.042$ respectively). However, there was no relationship with other characteristics, such as gender, age, B symptoms, extranodal site involvement and International Prognostic Index (IPI) (all $p_{\mathrm{s}}>0.05$ ).

Prognostic significance of serum miR-21 in patients with DLBCL:

The Kaplan-Meier analysis was performed to determine whether miR-21 was associated with OS. The overall DLBCL patients survival time was significantly lower in the high miR-21 group in comparison with the low miR-21 group (log rank test, $p=0.01$; Fig. (3)).

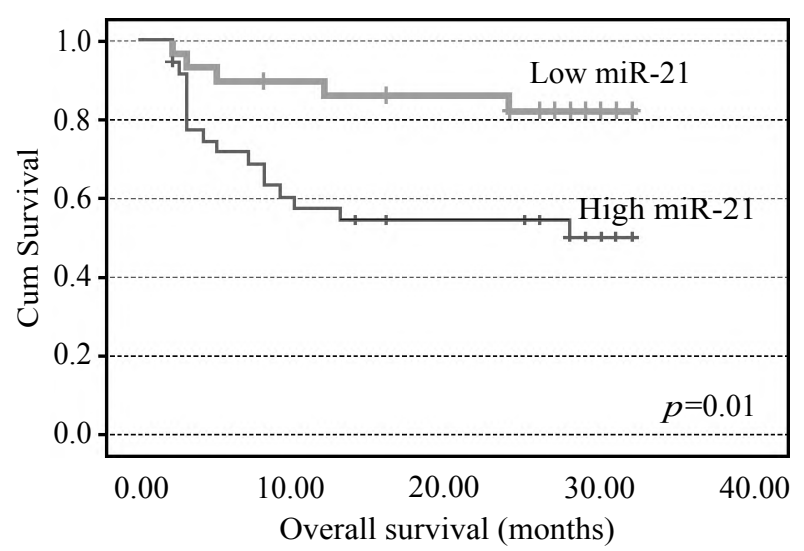

Fig. (3): Kaplan-Meier analysis of overall survival in DLBCL patients.

\section{Discussion}

The utilization of various circulating miRNAs as non-invasive cancer biomarkers has become important and promising field of research due to valuable characteristics of miRNAs such as particular miRNA expression profile for each cancer and high stability [16].

MiR-21 was identified for the first time as micro-oncogene in human glioblastoma by blocking the expression of essential apoptosis-associated genes [17]. An oncogenic function of miR-21 and its role in lymphomagenesis has been supported by its high expression in B-cell malignancies [1820]. Moreover miR-21 was documented to control the resistance of DLBCL cells to the CHOP based chemotherapy protocol [21]

A study by Li et al., [22] reported negative correlation between the expression of miR-21 and PTEN protein in DLBCL tissues, and suggested PTEN as one of the target cancer suppressor gene of miR-21 in DLBCL.

MiR-21 was previously documented to be overexpressed in DLBCL [22-24], while thorough analysis of this miRNA in serum samples of both DLBCL patients and healthy controls was rare, 
and its prognostic value showed conflicting results between different studies which might be explained by different types of samples, study cohort and therapy regimens $[24,25]$.

In the present study increased relative expression of serum miR-21 in DLBCL patients in comparison with healthy controls was revealed. This finding was consistent with the previous results reported by Li et al., [22], Go et al., [23], both studies analyzed miR-21 expression in DLBCL tissues, and also with Li et al., [24] who used serum samples for miR-21 expression estimation.

We also demonstrated that high MiR-21 expression levels were closely associated with advanced stage; poor response to therapy and elevated serum CRP, LDH and 32 microglobulin levels. However, there was no relationship with other patients' characteristics including gender, age, B symptoms, extranodal site involvement and IPI.

A number of previous studies have revealed the association between MiR-21; and different clinical features and laboratory findings of DLBCL patients. Similar to our results, Go et al., [23] detected that miR-21 was significantly overexpressed in DLBCL with advanced stage with no relationship found between miR-21 expression and other clinicopathological parameters as age, gender, B symptoms and extranodal site involvement.

Inconsistent with our results; $\mathrm{Li}$ et al., [24] demonstrated significant association between miR21 expression and the presence of B symptoms. However, no correlation was found with other features like stage and serum CRP.

In accordance with our results, Fu et al., [26] and Song et al., [27] revealed that miR-21 expression was correlated with clinical stage and serum LDH level. Zheng et al., [28] detected high miR-21 expression in DLBCL patients with advanced stage but no relationship was found between miR-21 expression and other characteristics including gender, age and extranodal site involvement.

Interestingly; our study revealed association between inferior OS and high miR-21 expression levels. Similarly, Go et al., [23] and Li et al., [24] showed that high expression of miR-21 was significantly associated with decreased overall survival. Against our findings, Munch-Petersen et al., [29] revealed no association between miR-21 expression on DLBCL tissue samples and overall survival.

In summary, we demonstrated that DLBCL patients with high expression of miR-21 had a significantly worse prognosis compared to DLBCL patients with low expression of miR-21. We also revealed significant association between miR-21 expression levels and various clinical and laboratory data.

With previous findings reported miR-21 as potent oncogene through down-regulation of multiple tumor suppressor genes; our findings provided serum miR-21 as promising valuable biomarker to predict the clinical outcome of DLBCL patients and as potential candidate for targeted therapy of DLBCL.

\section{Acknowledgements:}

Conflicts of interest: We have no conflicts of interest to disclose.

\section{References}

1- MENON M.P., PITTALUGA S. and JAFFE E.S.: The Histological and Biological Spectrum of Diffuse Large B-cell Lymphoma in the WHO Classification. Cancer J., 18 (5): 411-20, 2012.

2- XIE Y., PITTALUGA S. and JAFFE E.S.: The histological classification of diffuse large B-cell lymphomas. Semin. Hematol., 52 (2): 57-66, 2015.

3- CRUMP M., NEELAPU S.S., FAROOQ U., et al.: Outcomes in refractory diffuse large B-cell lymphoma: Results from the international SCHOLAR-1 study. Blood, 130 (16): 1800-8, 2017.

4- ZHENG Z., LI X., ZHU Y., et al.: Prognostic Significance of MiRNA in Patients with Diffuse Large B-Cell Lymphoma: A Meta-Analysis. Cell Physiol. Biochem., 39 (5): 1891-904, 2016.

5- PENG F., GUO L., YAO W.K., et al.: Identification of prognostic factors in patients with diffuse large B-cell lymphoma. Indian J. Pathol. Microbiol., 60 (1): 87-91, 2017.

6- RUPAIMOOLE R. and SLACK F.J.: MicroRNA therapeutics: Towards a new era for the management of cancer and other diseases. Nat. Rev. Drug Discov., 16 (3): 203 22, 2017.

7- ALENCAR A.J., MALUMBRES R., KOZLOSKI G.A., et al.: MicroRNAs are independent predictors of outcome in diffuse large B-cell lymphoma patients treated with RCHOP. Clin. Cancer Res., 17 (12): 4125-35, 2011.

8- MONTES-MORENO S.1., MARTINEZ N., SANCHEZESPIRIDIÓN B., et al.: MiRNA expression in diffuse large B-cell lymphoma treated with chemoimmunotherapy. Blood, 118 (4): 1034-040, 2011.

9- LUJAMBIO A. and LOWE S.W.: The microcosmos of cancer. Nature, 482 (7385): 347-55, 2012.

10- LINDAHL L.M., FREDHOLM S., JOSEPH C., et al.: STAT5 induces miR-21 expression in cutaneous T cell lymphoma. Oncotarget, 7 (29): 45730-44, 2016.

11- WANG J.H., ZHOU W.W., LIU B.X., et al.: Expression and significance of miR-21 in multiple myeloma patients. Genet. Mol. Res., 15 (1), 2016. 
12- WU Y., SONG Y., XIONG Y., et al.: MicroRNA-21 (Mir21) Promotes Cell Growth and Invasion by Repressing Tumor Suppressor PTEN in Colorectal Cancer. Cell Physiol. Biochem., 43 (3): 945-58, 2017.

13- PARK S., EOM K., KIM J., et al.: MiR-9, miR-21, and miR-155 as potential biomarkers for HPV positive and negative cervical cancer. B.M.C. Cancer, 17 (1): 658, 2017.

14- ASAGA S., KUO C., NGUYEN T., et al.: Direct serum assay for microRNA-21 concentrations in early and advanced breast cancer. Clin. Chem., 57 (1): 84-91, 2011.

15- YANG Y., GUO J.X. and SHAO Z.Q.: MiR-21 targets and inhibits tumor suppressor gene PTEN to promote prostate cancer cell proliferation and invasion: An experimental study. Asian Pac. J. Trop. Med., 10 (1): 87-91, 2017.

16- LARREA E., SOLE C., MANTEROLA L., et al.: New Concepts in Cancer Biomarkers: Circulating miRNAs in Liquid Biopsies. Int. J. Mol. Sci., 17. pii: E627, 2016.

17- CHAN J.A., KRICHEVSKY A.M. and KOSIK K.S MicroRNA-21 is an antiapoptotic factor inhuman glioblastoma cells. Cancer Res., 65 (14): 6029-33, 2005.

18- LAWRIE C.H., SONEJI S., MARAFIOTI T., et al.: MicroRNA expression distinguishes between germinal center B cell-like and activated B cell-like subtypes of diffuse large B cell lymphoma. Int. J. Cancer, 121: 115661, 2007.

19- FULCI V., CHIARETTI S., GOLDONI M., et al.: Quantitative technologies establish a novel microRNA profile of chronic lymphocytic leukemia. Blood, 109: 4944-51, 2007.

20- LAWRIE C.H., CHI J., TAYLOR S., et al.: Expression of microRNAs in diffuse large B cell lymphoma is associated with immunophenotype, survival and transformation from follicular lymphoma. J. Cell Mol. Med., 13: 124860, 2009.
21- BAI H., WEI J., DENG C., et al.: MicroRNA-21 regulates the sensitivity of diffuse large B-cell lymphoma cells to the CHOP chemotherapy regimen. Int. J. Hematol., 97: 223-31, 2013

22- LI C.H., FU R., WANG Y.H., et al.: Expression and clinical significance of miR-21 in diffuse large B cell lymphoma. Zhongguo Shi Yan Xue Ye Xue Za Zhi, 22: 339-43, 2014

23- GO H., JANG J.Y., KIM P.J., et al.: MicroRNA-21 plays an oncogenic role by targeting FOXO 1 and activating the $\mathrm{PI} 3 \mathrm{~K} / \mathrm{AKT}$ pathway in diffuse large B-cell lymphoma. Oncotarget, 6: 15035-49, 2015.

24- LI J., FU R., YANG L. and TU W.: MiR-21 expression predicts prognosis in diffuse large B-cell lymphoma. Int. J. Clin. Exp. Pathol., 8: 15019-24, 2015.

25- CHEN W., WANG H., CHEN H., et al.: Clinical significance and detection of microRNA-21 in serum of patients with diffuse large B-cell lymphoma in Chinese population. Eur. J. Haematol., 92: 407-12, 2014.

26- FU R., LI C. and SHAO Z.: Aberrant Overexpression and Regulatory Mechanism of Mir-21 in Diffuse Large B Cell Lymphoma. Blood, 124 (21): 5171, 2014.

27- SONG J., SHAO Q., LI C., et al.: Effects of microRNA21 on apoptosis by regulating the expression of PTEN in diffuse large B-cell lymphoma. Medicine (Baltimore), 96: e7952, 2017.

28- ZHENG Z., XU P.P., WANG L., et al.: MiR21 sensitized B-lymphoma cells to ABT-199 via ICOS/ICOSL-mediated interaction of Treg cells with endothelial cells. J. Exp. Clin. Cancer Res., 36: 82, 2017.

29- MUNCH-PETERSEN H.D., RALFKIAER U., SJÖ L.D., et al.: Differential expression of miR-155 and miR-21 in tumor and stroma cells in diffuse large B-cell lymphoma. Appl Immunohistochem. Mol. Morphol., 23 (3): 188-95, 2015. 


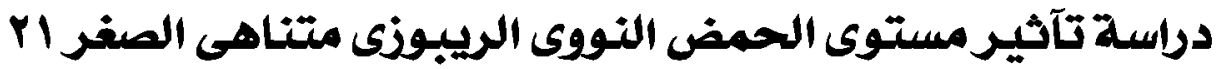

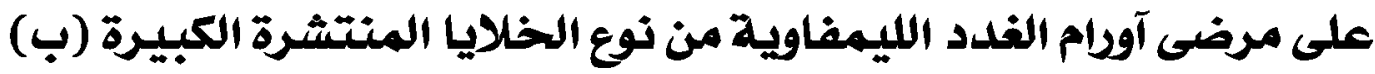

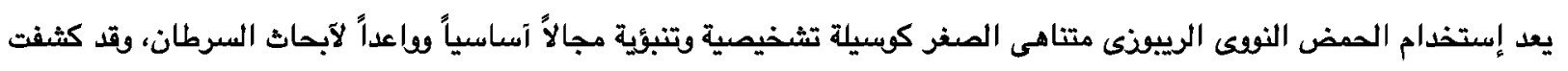

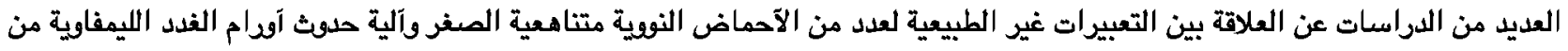
نوع الخلايا المنتشرة الكبيرة (ب). الهدف من الدراسة: تحليل مستويات التعبير النسبى لحمض النوفى الريبوذى متناهى الصغر الب وآيضا آهميته كعامل تنبؤ فى مرضى آودام الفدد الليمفاوية من نوع الخدايلايا المنتشرة الكبيرة (ب).

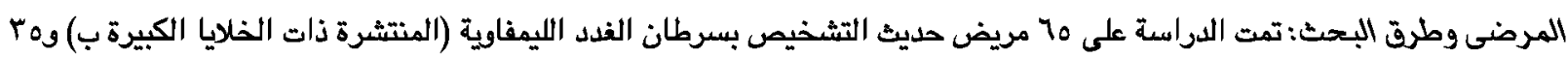

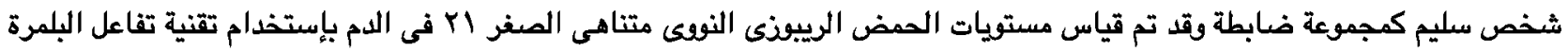

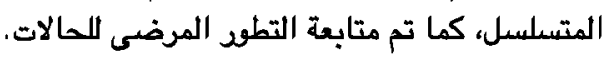

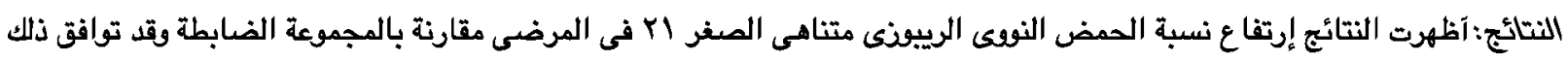

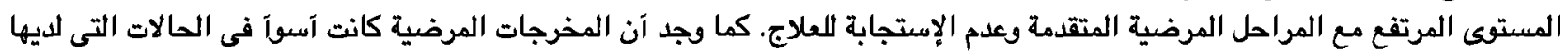

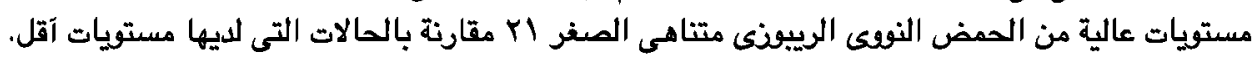
الملخص: يمكن إستخدام الحمض النويى الرييوزى متناهى الصغر الب كعامل تنبؤ فعال فى مرضى سرطان الغدل الليمفاوية (المنتشرة

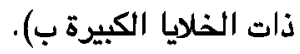

